\title{
Model Economic Production Quantity dengan Rework Process dan Batasan Gudang
}

\author{
Dana Marsetiya Utama*, Dwi Pramudia Wardani, Syukron Taufiqurrohman Halifah, \\ Dimas Caesario Pradikta \\ Program Studi Teknik Industri, Universitas Muhammadiyah Malang. JI. Raya Tlogomas No. 246 Malang 65144, Jawa Timur, \\ Indonesia
}

\section{ARTICLE INFORMATION}

Article history:

Received: Januari 25, 2019

Revised: April 18, 2019

Accepted: May 15, 2019

Kata Kunci:

Economic Production Quantity

Rework Process

Kapasitas Gudang

\section{Keywords:}

Economic Production Quantity

Rework Process

Constrained Space

${ }^{*}$ Corresponding Author

Dana Marsetiya Utama

E-mail: dana@umm.ac.id

\begin{abstract}
A B S T R A K
Produk rework dan kapasitas gudang merupakan permasalahan yang biasa dialami perusahaan dalam proses produksi. Beberapa model Economic Production Quantity (EPQ) dikembangkan untuk meminimalkan biaya pembelian bahan baku. Penelitian ini bertujuan untuk mengembangkan model Economic Production Quantity (EPQ) dengan rework process dan batasan gudang dengan asumsi produk yang tidak sempurna dapat dilakukan pengerjaan ulang. Model yang diusulkan mempertimbangkan beberapa komponen biaya diantaranya set up, holding, production, rework, dan gudang. Dua model yang diusulkan adalah model EPQ dengan rework dan biaya gudang, dan Model EPQ dengan rework dan batasan gudang. Berdasarkan beberapa pengujian yang dilakukan diperoleh peningkatan nilai jumlah persediaan maksimal yang tidak berdampak pada biaya produksi dan biaya rework process. Berdasarkan beberapa percobaan numerik, total biaya rework process, dan biaya produksi tidak berubah tehadap nilai jumlah persediaan maksimal.
\end{abstract}

\section{A B S T R A C T}

Rework products and warehouse capacity are common problems experienced by companies in the production process. Several Economic Production Quantity (EPQ) models were developed to minimize the costs of purchasing raw materials. This study aims to develop an Economic Production Quantity (EPQ) model with rework processes and warehouse constraints, assuming that the product is not perfect and can rework. The proposed model considers several cost components, including setup, holding, production, rework, and warehouse. The two proposed models are EPQ models with reworks and warehouse costs, and EPQ models with reworks and warehouse constraints. Based on several tests conducted, it obtains that the increase in the value of the maximum inventory amount did not have an impact on the production costs and the cost of the rework process. Based on several numerical experiments, the total cost of the rework process and production costs do not change to the maximum inventory value.

This is an open access article under the CC-BY-NC-SA license.

\section{PENDAHULUAN}

Bahan baku merupakan kunci utama perusahaan untuk menunjang kelancaran produksi [1], [2], dan [3]. Penyediaan bahan baku disetiap perusahaan harus direncanakan dengan baik [4]. Persediaan adalah bahan yang tersimpan dalam gudang untuk digunakan ataupun dijual. Bahan baku tersebut digunakan untuk membuat produk. Dalam prosesnya produk yang dibuat ada yang tidak sempurna yang dikenal dengan produk cacat [5]. Beberapa produk cacat dapat dilakukan rework process untuk meminimalkan kerugian perusahaan [6]. 
Model Economic Production Quantity (EPQ) merupakan model penentuan produksi dengan mempertimbangkan biaya pengadaan maupun persediaan [7]. Beberapa penelitian mengembangkan model EPQ dengan memasukkan parameter rework process yang bertujuan minimasi biaya pembelian bahan baku [8], [9],[10], [11], dan [12].

Penelitian model EPQ dengan rework process umumnya diusulkan untuk meminimalisir permasalahan biaya yang berkaitan dengan hasil produk yang sempurna dan yang tidak sempurna. Model ini dibangun untuk memperoleh waktu siklus optimal yang akan meminimalkan total biaya tahunan [13]. Pada perkembangannya model EPQ dengan rework process dikombinasikan dengan pertimbangan rework dan imperfect quality [14], maupun dengan mempertimbangkan kualitas produk yang tidak sesuai, backlogging, dan kegagalan produksi [15], [16], dan [17]. Selain model EPQ dengan rework, Chiu, Wang, and Chiu [12] mengusulkan model persediaan EPQ dengan scrap, rework, dan kerusakan mesin. Aplikasi $\mathrm{EPQ}$ dikembangkan pada kasus single stage [18], [19], dan [20] maupun multi-stage [21], [22]. Model tersebut kemudian dikembangkan dengan memperhatikan keterbatasan gudang [23], [24], dan [25].

Uraian di atas menunjukkan banyak penelitian penentuan jumlah pemesanan ekonomis, yang mengadopsi riset dari Pasandideh, Niaki, and Mirhosseyni [7] dengan parameter rework process dengan pertimbangan kapasitas gudang. Parameter ini dipilih dengan asumsi produk yang tidak sempurna dapat diperbaiki. Hasil penelitian ini diharapkan dapat menjadi sebuah solusi dalam menyelesaikan sebuah permasalahan yang berkaitan dengan persediaan bahan baku yang tidak sempurna dengan rework process serta penentuan lot size yang mempertimbangkan batasan kapasitas gudang. Beberapa komponen biaya yang digunakan diantaranya setup, holding, production, rework, dan gudang

\section{METODE PENELITIAN}

Beberapa asumsi dari permasalahan model usulan adalah sebagai berikut: (1) permintaan, biaya set up, biaya produksi, tingkat permintaan harian, biaya simpan, biaya rework, kapasitas gudang, dan proporsi defect dalam satu periode adalah tetap, (2) komponen pada asumsi (1) memiliki sifat deterministik, (3) model digunakan untuk 1 item produk, (4) modal yang dimiliki perusahaan tidak terbatas. Model EPQ dalam penentuan Total Cost dengan proses pengulangan telah dikembangkan oleh peneliti sebelumnya.

Notasi-notasi yang digunakan dalam model EPQ [12] ini antara lain:

\begin{tabular}{|c|c|}
\hline$D$ & $\begin{array}{l}\text { : Permintaan pada satu periode } \\
\text { perencanaan }\end{array}$ \\
\hline$S c$ & : Setup Cost \\
\hline$p$ & : Tingkat Pertambahan persediaan \\
\hline$P$ & : Production Cost \\
\hline$d$ & $\begin{array}{l}\text { : Tingkat Permintaan (D/ banyaknya hari } \\
\text { kerja dalam } 1 \text { tahun) }\end{array}$ \\
\hline$H c$ & : Holding Cost \\
\hline$Q$ & $\begin{array}{l}\text { : Jumlah pertambahan persediaan } \\
\text { (Kuantitas) }\end{array}$ \\
\hline$C p$ & : Rework Cost \\
\hline$o$ & : Pemakaian ruangan per unit $/ \mathrm{m}^{3}$ \\
\hline$F$ & $\begin{array}{l}\text { : Fasilitas untuk menyimpan persediaan } \\
\text { maksimum }\left(\mathrm{m}^{3}\right)\end{array}$ \\
\hline$\lambda$ & : Variable lagrange \\
\hline$\beta$ & : Proporsi defektif produk \\
\hline$T C$ & : Total Biaya Persediaan \\
\hline$Q$ & : Jumlah Persediaan maksimal \\
\hline$T C^{*}$ & $\begin{array}{l}\text { Total Biaya Persediaan dengan } \\
\text { batasan kapasitas gudang }\end{array}$ \\
\hline$Q^{*}$ & $\begin{array}{l}\text { : Jumlah Persediaan maksimal dengan } \\
\text { batasan kapasitas gudang }\end{array}$ \\
\hline
\end{tabular}

\section{Komponen Biaya Model EPQ Dasar}

Pada Model EPQ dasar, terdapat beberapa komponen biaya yang digunakan. Komponen biaya tersebut diantaranya adalah biaya set up produksi, biaya produksi, dan biaya simpan (persamaan 1). Komponen biaya yang kedua adalah biaya produksi (persamaan 2).

$\frac{D C}{Q}$
$D P$

Komponen biaya berikutnya dalam model dasar EPQ adalah biaya simpan (persamaan 3). Dengan menjumlahkan ketiga komponen biaya dan melakukan turunan pertama terhadap nilai $\mathrm{Q}$, maka model $E P Q$, dapat dilihat pada persamaan 4.

$$
\begin{aligned}
& \frac{Q H}{2}\left(1-\frac{d}{p}\right) \\
& Q=\frac{\sqrt{2 D C}}{\sqrt{H\left(\frac{p-d}{p}\right)}}
\end{aligned}
$$




\section{Model EPQ Usulan tanpa Batasan}

Model yang diusulkan dikembangkan dengan menambahkan biaya rework process dan biaya gudang. Pada model EPQ usulan, biaya rework process diformulasikan pada persamaan 5 . Persamaan ini mempertimbangkan presentasi defektiv produk, jumlah permintaan, dan biaya rework process per unit. Formula biaya rework process dapat dilihat sebagai berikut.

$D c p \beta$

Biaya gudang diformulasikan dengan menggunakan pemakaian gudang peunit, biaya gudang dan kuantitas yang disimpan dalam satu siklus. Biaya gudang umumnya diidentikan dengan biaya sewa gudang dalam satu siklus persediaan. Formula biaya pemakaian gudang dapat dilihat pada persamaan 6

Qgo

Selanjutnya, persamaan $1-5$ dijumlahkan untuk menghasilkan TC pada EPQ. Formula total biaya persediaan dari model yang diusulkan dapat dilihat pada persamaan 7. Untuk mendapatkan nilai $\mathrm{Q}$ optimal, persamaan 7 dilakukan penurunan pertama terhadap $Q$ (persamaan 8).

$T C=\frac{D C}{Q}+D P+\frac{Q H\left(1-\frac{d}{p}\right)}{2}+D c p \beta+Q g o$

$Q=\frac{\sqrt{2 D C}}{\sqrt{2 g o+H\left(\frac{p-d}{p}\right)}}$

Kemudian dari persamaan 8 disubtitusikan ke dalam persamaan 7 untuk menentukan nilai TC optimal pada EPQ. Formula TC optimal dapat dilihat pada persamaan 9 .

\section{Model EPQ Usulan dengan Batasan}

Pada sub bab sebelumnya sudah diuraikan model EPQ usulan tanpa mempertimbangkan batasan gudang. Namun, nilai $Q$ pada persamaan 7 memiliki batasan kapasitas gudang yang dimiliki perusahaan. Formula batasan kapasitas gudang dapat dilihat di persamaan 10.

Model persamaan 7 dan 10 apabila digabungkan menghasilkan sebuah formula Lagrange pada EPQ dengan pertimbangan batasan gudang yang dapat dilihat pada persamaan 11 .

Persamaan Lagrange (11) diturunkan parsial terhadap nilai $Q$ dan $\lambda$. Hasil turunan parsial terhadap nilai $Q$ dapat dilihat pada persamaan 12. Selanjutnya hasil turunan pertama persamaan (11) terhadap $\lambda$ disubstitusikan ke persamaan 12 menghasilkan nilai variabel $\lambda$ seperti pada persamaan 13

$T C=\frac{\left((D)(C p \beta) \sqrt{2 g o+H\left(\frac{p-d}{p}\right)}+\sqrt{2 D C}\left(2 g o+H\left(\frac{p-d}{p}\right)\right)\right)}{\sqrt{2 g o+H\left(\frac{p-d}{p}\right)}}$

$Q o \leq F$

$L(Q, \lambda)=\frac{D C}{Q}+D P+\frac{Q H\left(1-\frac{d}{p}\right)}{2}+D c p \beta+Q g o+$

$\lambda(Q o-F)$

$Q^{*}=\frac{\sqrt{2} D C}{\sqrt{H\left(\frac{p-d}{p}\right)+(2 g+2 \lambda) o}}$

$\lambda=\frac{2 o^{2} D C-2 g F^{2} o-H\left(\frac{p-d}{p}\right) F^{2}}{2 F^{2} o}$

Untuk mencari TC optimal pada EPQ dengan batasan tempat, persamaan 12 disubstitusikan ke persamaan 7. Formula TC dilihat pada persamaan 14.

\section{Analisa Sensitivitas Model}

Analisa sensitivitas pada model EPQ usulan adalah sebagai berikut: apabila nilai lambda $(\lambda)$ pada persamaan 13 menghasilkan nilai positif $(\lambda>0)$ maka formula $Q$ optimal yang digunakan adalah persamaan 12 . Selanjutnya, apabila nilai lambda $(\lambda)$ negatif $(\lambda<0)$ maka formula $Q$ optimal yang digunakan ialah persamaan 8 .

\section{Prosedur Percobaan}

Pada penelitian ini, dilakukan 20 percobaan dengan variasi modal fasilitas gedung yang berbeda, serta menggunakan modal minimum 100 sampai modal maksimum sebesar 10000 . Percobaan ini menggunakan pemakaian ruang per unit $(o)$ sebesar 1, demand $(D): 75000$, setup cost $(S c)$ : 120, holding cost $(h): 5$, biaya pemakaian gudang $(g)$ : 2, tingkat permintaan $(d)$ : 300, tingkat pertambahan persediaan $(p)$ : 500 , jumlah pertambahan persediaan $(Q)$ : 10000 , production cost $(P): 5$, proporsi defektif produk $(\beta): 0.1$, rework cost $(C p): 6$, dan fasilitas penyimpanan persediaan maksimum $(F): 10000$. 


\section{HASIL DAN PEMBAHASAN}

Telah dilakukan 20 percobaan model EPQ usulan dengan beberapa contoh kasus. Hasil percobaan dapat dilihat pada Gambar 1 dan Tabel 1. Pada Gambar 1, hasil percobaan model EPQ menunjukkan bahwa biaya produksi $(D P)$ dan biaya rework process $(D C p \beta)$ tidak dipengaruhi oleh $Q$. Hasil tersebut menunjukan semakin besar nilai $Q$ tidak berdampak pada biaya produksi $(D P)$ dan biaya rework process $(D C p \beta)$. Hal ini disebabkan karena formula biaya produksi dan biaya rework process tidak dipengaruhi oleh Q. Selanjutnya, pada biaya pesan, hasil percobaan menunjukan bahwa semakin besar nilai $Q$ maka total biaya pesan semakin kecil. Pada biaya simpan, semakin besar nilai $Q$ maka total biaya simpan semakin besar. Seperti halnya pada biaya simpan, pada biaya gudang, semakin besar nilai $Q$ maka total biaya gudang semakin besar.

Berdasarkan Tabel 1, terdapat 20 percobaan dengan nilai fasilitas gudang bervariasi. Dapat disimpulkan bahwa semakin kecil nilai lambda $(\lambda)$, maka nilai total biaya persediaan semakin besar. Sebaliknya, semakin besar nilai $\lambda$, maka nilai total biaya persediaan juga semakin besar. Total biaya persediaan optimal (TC) diperoleh apabila nilai $\lambda=0$. Dari percobaan pada Tabel 1 juga, apabila Q.o < F, maka formula yang digunakan dalam penentuan jumlah kuantitas optimal adalah menggunakan formula pada persamaan 8. Sebaliknya, apabila Q.o $>$ F, maka formula yang digunakan dalam penentuan jumlah kuantitas optimal adalah menggunakan formula pada persamaan 12 .

Berdasarkan beberapa percobaan numerik, total biaya rework process (persamaan 2) dan biaya produksi (persamaan 5) tidak berubah tehadap nilai Q. Hasil ini menunjukan bahwa, dalam 1 horison perencanaan (tahun) biaya rework process (persamaan 2) dan biaya produksi (persamaan 5) adalah tetap. Pada komponen biaya simpan (persamaan 3 ) dan biaya gudang (persamaan 6) terdapat beberapa temuan, semakin besar $Q$ maka biaya simpan (persamaan 3) dan biaya gudang (persamaan 6) semakin besar. Sebaliknya, semakin kecil $Q$ maka biaya simpan (persamaan 3) dan biaya gudang (persamaan 6) semakin kecil. Lebih lanjut, pada biaya total biaya pesan (persamaan 1), semakin besar $Q$ maka total biaya pesan semakin kecil. Sebaliknya, semakin kecil Q maka total biaya pesan semakin besar. Total biaya minimum diperoleh dari total biaya rework process, biaya produksi, biaya simpan, biaya gudang dan biaya pesan

$T C^{*}=\frac{\left((D)(C p \beta+P) \sqrt{2 g o+H\left(\frac{p-d}{p}\right)}+(2 g+2 \lambda) o+\sqrt{2}+\sqrt{C}\left(H\left(\frac{p-d}{p}\right)+o(\lambda+2 g)+\right) \sqrt{D}\right)}{\sqrt{H\left(\frac{p-d}{p}\right)}+(2 g+2 \lambda) o}$

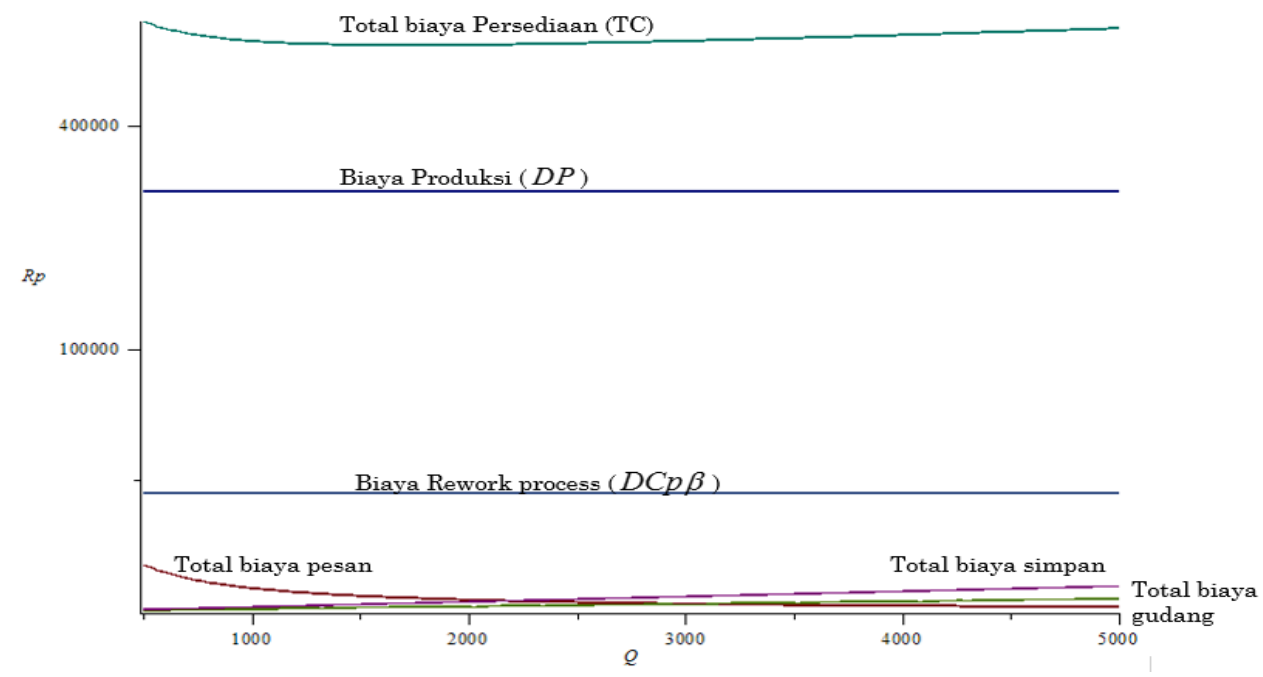

Gambar 1. Hubungan komponen biaya terhadap nilai $Q$ 
Tabel 1. Rekapitulalsi hasil perhitungan total cost (TC) dengan batasan gudang

\begin{tabular}{|c|c|c|c|c|c|c|}
\hline Percobaan & $\mathrm{F}$ & $Q$ & TC & $\lambda$ & $Q^{*}$ & $\mathrm{TC}^{*}$ \\
\hline 1 & 100 & 1414 & $\operatorname{Rp} 432.727,00$ & 895,5 & 100 & $\operatorname{Rp} 510.450,00$ \\
\hline 2 & 200 & & & 220,5 & 200 & $\mathrm{Rp} 465.900,00$ \\
\hline 3 & 350 & & & 68,97 & 350 & Rp 447.289,00 \\
\hline 4 & 400 & & & 51,75 & 400 & $\operatorname{Rp} 444.300,00$ \\
\hline 5 & 550 & & & 25,25 & 550 & $\mathrm{Rp} 438.838,00$ \\
\hline 6 & 600 & & & 20,5 & 600 & $\mathrm{Rp} 437.700,00$ \\
\hline 7 & 900 & & & 6,61 & 900 & $\mathrm{Rp} 434.050,00$ \\
\hline 8 & 1000 & & & 4,5 & 1000 & $\operatorname{Rp} 433.500,00$ \\
\hline 9 & 1300 & & & 0,83 & 1300 & $\mathrm{Rp} 432.773,00$ \\
\hline 10 & 1500 & & & $-0,5$ & 1500 & $\mathrm{Rp} 432.750,00$ \\
\hline 11 & 2000 & & & $-2,25$ & 2000 & $\mathrm{Rp} 433.500,00$ \\
\hline 12 & 2500 & & & $-3,06$ & 2500 & $\operatorname{Rp} 434.850,00$ \\
\hline 13 & 3000 & & & $-3,5$ & 3000 & $\mathrm{Rp} 436.500,00$ \\
\hline 14 & 4000 & & & $-3,94$ & 4000 & $\mathrm{Rp} 440.250,00$ \\
\hline 15 & 5000 & & & $-4,14$ & 5000 & $\mathrm{Rp} 444.300,00$ \\
\hline 16 & 6000 & & & $-4,25$ & 6000 & $\mathrm{Rp} 448.500,00$ \\
\hline 17 & 7000 & & & $-4,32$ & 7000 & $\mathrm{Rp} 452.785,00$ \\
\hline 18 & 8000 & & & $-4,36$ & 8000 & $\mathrm{Rp} 457.125,00$ \\
\hline 19 & 9000 & & & $-4,39$ & 9000 & $\operatorname{Rp} 461.500,00$ \\
\hline 20 & 10000 & & & $-4,41$ & 10000 & $\operatorname{Rp} 465.900,00$ \\
\hline
\end{tabular}

\section{KESIMPULAN}

Penelitian ini mengembangkan model Economic Production Quantity (EPQ) dengan rework process dan batasan gudang. Model EPQ usulan mempetimbangkan beberapa biaya diantaranya set up, holding, production, rework dan gudang. Kuantitas produksi optimal diperoleh berdasarkan komponen biaya penyusun EPQ. Beberapa percobaan dilakukan untuk menguji model yang diusulkan. Studi ini memberikan wawasan dalam merancang EPQ model persediaan dengan batasan gudang dan pengerjaan ulang. Penelitian selanjutnya diharapkan dapat mempertimbangkan faktor karbon emisi yang dikeluarkan dari aktivitas produksi.

\section{UCAPAN TERIMA KASIH}

Terimakasih kami ucapkan kepada Universitas Muhammadiyah Malang yang telah memberikan fasilitas dalam menyelesaikan artikel ini. Kami juga mengucapkan terima kasih kepada Laboratorium Optimasi dan Simulasi Industri dalam penyelesaian artikel IImiah ini.

\section{REFERENSI}

[1] D. Marsetiya Utama, "Model Penentuan Lot Pemesanan Dengan Mempertimbangkan Unit Diskon dan Batasan Kapasitas Gudang dengan Program Dinamis," J. Tek. Ind., vol. 18, no. 1, pp. 94-102, Aug. 2017, doi: 10.22219/jtiumm.vol18.no1.94-102.

[2] D. M. Utama, "Model Program Dinamis Dalam Penentuan Lot Pemesanan dengan Mempertimbangkan Batasan Modal," in Prosiding SENTRA (Seminar Teknologi dan Rekayasa), 2017, pp. 1-6, available at: http://researchreport.umm.ac.id/index.php/sentra/article/ view/1463.

[3] D. M. Utama, "Penentuan Lot Size Pemesanan Bahan Baku Dengan Batasan Kapasitas Gudang," J. IIm. Tek. Ind., vol. 15, no. 1, pp. 64-68, Jul. 2017, doi: $10.23917 / j$ jiti.v15i1.1664.

[4] D. M. Utama, "Model Program Dinamis Untuk Lot Size Multi Item dengan Kendala Kapasitas Gudang," J@ti Undip J. Tek. Ind., vol. 14, no. 1, pp. 21-26, May 2019, doi: 10.14710/jati.14.1.21-26. 
[5] A. H. Tai, "Economic production quantity models for deteriorating/imperfect products and service with rework," Comput. Ind. Eng., vol. 66, no. 4, pp. 879-888, Dec. 2013, doi: 10.1016/j.cie.2013.09.007.

[6] B. Sarkar, L. E. Cárdenas-Barrón, M. Sarkar, and M. L. Singgih, "An economic production quantity model with random defective rate, rework process and backorders for a single stage production system," J. Manuf. Syst., vol. 33, no. 3, pp. 423-435, Jul. 2014, doi: 10.1016/j.jmsy.2014.02.001.

[7] S. H. R. Pasandideh, S. T. A. Niaki, and S. S. Mirhosseyni, "A parameter-tuned genetic algorithm to solve multi-product economic production quantity model with defective items, rework, and constrained space," Int. J. Adv. Manuf. Technol., vol. 49, no. 5-8, pp. 827-837, Jul. 2010, doi: 10.1007/s00170-009-2432-x.

[8] K.-J. Chung, "The economic production quantity with rework process in supply chain management," Comput. Math. with Appl., vol. 62, no. 6, pp. 2547-2550, Sep. 2011, doi: 10.1016/j.camwa.2011.07.039.

[9] Y.-S. P. Chiu, "Determining the optimal lot size for the finite production model with random defective rate, the rework process, and backlogging," Eng. Optim., vol. 35, no. 4, pp. 427-437, Aug. 2003, doi: 10.1080/03052150310001597783.

[10] A. A. Taleizadeh, L. E. Cárdenas-Barrón, J. Biabani, and R. Nikousokhan, "Multi products single machine EPQ model with immediate rework process," Int. J. Ind. Eng. Comput., vol. 3, no. 2, pp. 93-102, Jan. 2012 , doi:10.5267/j.ijiec.2011.09.001.

[11] S. Khalilpourazari and S. H. R. Pasandideh, "Bi-objective optimization of multi-product EPQ model with backorders, rework process and random defective rate," in 2016 12th international conference on industrial engineering (ICIE), 2016, pp. 36-40, available at: 10.1109/INDUSENG.2016.7519346.

[12] S. W. Chiu, S.-L. Wang, and Y. P. Chiu, "Determining the optimal run time for EPQ model with scrap, rework, and stochastic breakdowns," Eur. J. Oper. Res., vol. 180, no. 2, pp. 664-676, Jul. 2007, doi: 10.1016/j.ejor.2006.05.005.

[13] M. J. Rosenblatt and H. L. Lee, "Economic Production Cycles with Imperfect Production Processes," IIE Trans., vol. 18, no. 1, pp. 48-55, Mar.
1986, doi: 10.1080/07408178608975329.

[14] P. A. Hayek and M. K. Salameh, "Production lot sizing with the reworking of imperfect quality items produced," Prod. Plan. Control, vol. 12, no. 6, pp. 584-590, Jan. 2001, doi: 10.1080/095372801750397707.

[15] Y. Peter Chiu and S. Wang Chiu, "A finite production model with random defective rate and shortages allowed and backordered," J. Inf. Optim. Sci., vol. 24, no. 3, pp. 553-567, Sep. 2003, doi: 10.1080/02522667.2003.10699584.

[16] S. W. Chiu and Y.-S. P. Chiu, "Mathematical modeling for production system with backlogging and failure in repair," J. Sci. Ind. Res., vol. 65, no. 6, p. 499 $=506, \quad 2006$, available at: http://nopr.niscair.res.in/handle/12345678 9/4847.

[17] S. Wang Chiu, "Optimal replenishment policy for imperfect quality EMQ model with rework and backlogging," Appl. Stoch. Model. Bus. Ind., vol. 23, no. 2, pp. 165-178, Nov. 2006, doi: 10.1002/asmb.664.

[18] L. E. Cárdenas-Barrón, "Economic production quantity with rework process at a single-stage manufacturing system with planned backorders," Comput. Ind. Eng., vol. 57, no. 3, pp. 1105-1113, Oct. 2009, doi: 10.1016/j.cie.2009.04.020.

[19] H.-M. Wee, W.-T. Wang, and L. E. Cárdenas-Barrón, "An alternative analysis and solution procedure for the EPQ model with rework process at a single-stage manufacturing system with planned backorders," Comput. Ind. Eng., vol. 64, no. 2, pp. 748-755, Feb. 2013, doi: 10.1016/j.cie.2012.11.005.

[20] E. Shekarian, M. Y. Jaber, N. Kazemi, and $E$. Ehsani, "A fuzzified version of the economic production quantity (EPQ) model with backorders and rework for a single-stage system," Eur. J. Ind. Eng., vol. 8, no. 3, pp. 291-324, 2014, doi: 10.1504/EJIE.2014.060998.

[21] B. R. Sarker, A. M. M. Jamal, and S. Mondal, "Optimal batch sizing in a multistage production system with rework consideration," Eur. J. Oper. Res., vol. 184, no. 3, pp. 915-929, Feb. 2008, doi: 10.1016/j.ejor.2006.12.005.

[22] G. A. Widyadana and H. M. Wee, "An economic production quantity model for deteriorating items with multiple production setups and rework," Int. J. Prod. Econ., vol. 138, no. 1, pp. 62-67, 
Jul. 2012, doi: 10.1016/j.ijpe.2012.02.025.

[23] S. H. R. Pasandideh and S. T. A. Niaki, "A genetic algorithm approach to optimize a multi-products EPQ model with discrete delivery orders and constrained space," Appl. Math. Comput., vol. 195, no. 2, pp. 506-514, Feb. 2008, doi: 10.1016/j.amc.2007.05.007.

[24] S. H. R. Pasandideh, S. T. A. Niaki, and J. A. Yeganeh, "A parameter-tuned genetic algorithm for multi-product economic production quantity model with space constraint, discrete delivery orders and shortages," Adv. Eng. Softw., vol. 41, no. 2, pp. 306-314, Feb. 2010, doi: 10.1016/j.advengsoft.2009.07.001.

[25] S. Islam and T. K. Roy, "A fuzzy EPQ model with flexibility and reliability consideration and demand dependent unit production cost under a space constraint: A fuzzy geometric programming approach," Appl. Math. Comput., vol. 176, no. 2, pp. 531-544, May 2006, doi: 10.1016/j.amc.2005.10.001. 